\title{
Article
}

\section{A Quick Guide to Statistical Modeling Design Defects, Product Liability and the Protective Properties of Suboptimal Nonparametric and Robust Statistics}

\author{
Michael Lang 1,* (10) \\ 1 Graduate School of Excellence Computational Engineering, Technische Universtät Darmstadt, Dolivostraße 15, 64293 \\ Darmstadt, Germany; Tel.: +496151 1624401, Fax: 4961511624404 \\ * Correspondence: michael.lang@ieee.org
}

\begin{abstract}
Statistical modeling lies at the heart of product design and development throughout numerous engineering disciplines, especially since processing large amounts of data has become increasingly ubiquitous. While mathematical statistics provide elegant guidance pertaining to the question of whether or not some particular underlying modeling assumptions are justified and appropriate, when pursuing a more comprehensive assessment of product design and development other considerations often increase in significance. Therefore, we will examine and analyze the tedious interactions and implications of statistical modeling choices and product liability exposure. To the best of our knowledge, this paper is the first to draw attention to and explore some often overlooked or oversimplified dangers and pitfalls that enter the equation when product design heavily relies on statistical modeling. In particular, through a diligent analysis of both statistical and legal aspects we will explore how statistically optimal procedures may yield far from optimal outcomes in terms of product liability when applied to actual real life problems and why suboptimal nonparametric or robust approaches may constitute better alternatives.
\end{abstract}

Keywords: product design; design defect; robust statistics; nonparametric statistics; model uncertainty; optimization; liability; tortious product liability; strict product liability

\section{Introduction}

IoT, Big Data, Machine and Deep Learning and related technologies first and foremost leverage the power of Statistics, a discipline which may be described as the art and science of the analysis and interpretation of data. A crucial commonality encountered in all statistical endeavors lies in the necessity to impose modeling assumptions, be they explicit or implicit in nature, on the observed data.

As will be shown in Section 2 and exemplified by the pitfalls of the ubiquitous Gaussian assumption, the detrimental ramifications arising from an adherence to unrealistic modeling assumptions have been known for centuries and eventually led to the development of the field of robust statistics and formal robustness theories in the early 1960s. Somewhat ironically however, the stoic quest for optimal robust procedures made them vulnerable to some of the same perils they initially set out to tackle. Nonparametric and distribution-free approaches on the other hand, while being more broadly applicable, are frequently dismissed as too conservative and poor performing. The main focus of this paper however is not to reiterate decades-old debates pertaining to philosophical aspects of mathematical statistics, which is why Section 2 is exemplary and purposely non-exhaustive.

To the best of our knowledge, this paper is the first to draw attention to and explore some often overlooked or oversimplified dangers and pitfalls that enter the equation when product design heavily relies on statistical modeling. In Section 3, from an engineering perspective, we will comprehensibly and exhaustively develop the relevant pathways allowing for flaws in the initial modeling to yield to civil liability ${ }^{1}$ for various actors involved.

wherein our focus will be on the German jurisdiction, although due to European harmonization most aspects hold for all European Member States and can furthermore partly be extrapolated to other parts of the world. 
We will emphasize that, unbeknownst to many in the engineering community, civil liability for defective products cannot simply be excluded through general terms and conditions or other means and ought therefore be taken into account from the very early stages of product design and development. Conceding that due to importance and weight of case-specific circumstances no general solution or guidance can responsibly be provided, Section 4 aims at providing the reader with a concise summary of the most relevant findings and some broad recommendations. Finally, Section 5 concludes this paper with a short discussion.

\section{Statistical Approaches}

In the following basic concepts will be introduced together with the historical context in which they arose. Customarily a distinction between parametric and nonparametric approaches is drawn, representing approaches that favor efficiency over validity and vice-versa, respectively, as depicted in Table 1.

Table 1. Overview of statistical approaches: Parametric, Robust, Nonparametric

\begin{tabular}{|c|c|c|c|}
\hline & \multicolumn{3}{|c|}{ Statistical approaches } \\
\hline & Parametric & Robust & $\begin{array}{c}\text { Nonparametric } \\
\text { ('Distribution-free') }\end{array}$ \\
\hline $\begin{array}{l}\text { Distributional } \\
\text { Assumptions }\end{array}$ & $\begin{array}{l}\text { Specific distribution } \\
\text { function, characterized by a } \\
\text { fixed and low-dimensional } \\
\text { set of parameters }\end{array}$ & $\begin{array}{l}\text { Parametric model allowing } \\
\text { for small deviations from } \\
\text { the nominal assumptions }\end{array}$ & $\begin{array}{l}\text { No particular distributional } \\
\text { assumptions }\end{array}$ \\
\hline Characteristics & $\begin{array}{l}\text { 'Optimal' performance } \\
\text { may be achieved assuming } \\
\text { the underlying model } \\
\text { assumptions are met exactly }\end{array}$ & $\begin{array}{l}\text { 'Nearly optimal' } \\
\text { performance under } \\
\text { the nominal model } \\
\text { while maintaining } \\
\text { good performance in } \\
\text { the (moderate) presence of } \\
\text { outliers or model mismatch }\end{array}$ & $\begin{array}{l}\text { Sub-optimal, yet acceptable } \\
\text { performance over broad } \\
\text { range of distributions }\end{array}$ \\
\hline 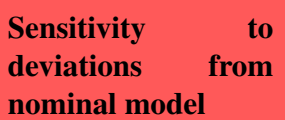 & Very high & Moderate to low & - \\
\hline
\end{tabular}

Robust approaches, accordingly, can be thought of as pursuing a compromise between the two aforementioned extremes in that they should exhibit near optimal behavior if the nominal model indeed provides an accurate representation of the underlying data generating process(es) while at the same time exhibiting deteriorated, yet still acceptable performance in the case of small to moderate deviations from the nominal model ('model-mismatch') or in the case of contamination by a certain amount of (possibly arbitrarily high) extrinsic disturbances ('outliers').

\subsection{Normality Assumption, Maximum Likelihood and Least Squares}

Consider the basic problem of observing a fixed but unknown value $\mu$ contaminated by random errors $X_{n}$,

$$
Y_{n}=\mu+X_{n}
$$

with $X_{n} \sim \mathcal{N}\left(0, \sigma^{2}\right)$ and thus $Y_{n} \sim \mathcal{N}\left(\mu, \sigma^{2}\right)$, i.e. the probability density function (p.d.f.) of the random variable $Y$ is given by

$$
f_{Y}(y)=\frac{1}{\sqrt{2 \pi} \sigma} \exp \left[-\frac{(y-\mu)^{2}}{2 \sigma^{2}}\right]
$$


which may also be written as $f_{Y}(y ; \theta)$ with $\theta=\left[\mu, \sigma^{2}\right]$ being the finite set of distributional parameters or distributional parameter vector that completely specifies the p.d.f. The construction of an estimator shall be exemplified by illustrating the maximum-likelihood and least-squares approach to obtain $\hat{\mu}$.

\subsubsection{Maximum Likelihood Estimator}

The standard method for obtaining $\hat{\mu}$ in the above-mentioned estimation problem is given by the maximum likelihood approach and was introduced by R. A. Fisher in 1922 [1]. Given $n=1, \ldots, N$ i.i.d. observations $y_{1}, \ldots, y_{N}$ of $Y_{n}$, the joint probability density function is given by the product of the individual densities, i.e.

$$
f\left(y_{1}, \ldots, y_{N} ; \theta\right)=\prod_{i=1}^{N} f\left(y_{i} ; \theta\right)=L(\theta ; y)
$$

with $L(\theta ; y)$ being the likelihood function, a function of the unknown distributional parameter vector $\theta$ conditioned on the observed data sample $y=\left[y_{1}, \ldots, y_{N}\right]$. The likelihood function $L(\theta ; y)$ can be interpreted as pertaining to the probability of observing exactly the specific dataset at hand, i.e. $y_{1}, \ldots, y_{N}$, for a particular $\theta$. Then, searching for estimates $\hat{\theta}$ such that $L(\hat{\theta} ; y)$ is maximized yields parameters for the assumed distribution that result in the highest probability of 'producing' the observed data. Since the natural logarithm is a monotonically increasing function, maximizing the more tractable $\ln L(\theta ; y)$ yields to the same result as maximizing $L(\theta ; y)$. Accordingly, rather than working with the likelihood function of Eq. (3) one conventionally works with the log-likelihood function

$$
\ln L(\theta ; y)=\sum_{i=1}^{N} \ln f\left(y_{i} ; \theta\right)
$$

instead. Applied to the problem formulated in Eq. (1) this yields

$$
\ln L(\theta ; y)=-\frac{N}{2} \ln (2 \pi)-\frac{N}{2} \ln \sigma^{2}-\frac{1}{2} \sum_{i=1}^{N}\left[\frac{\left(y_{i}-\mu\right)^{2}}{\sigma^{2}}\right]
$$

The so-called likelihood-equation provides the necessary condition for maximizing the log-likelihood function, namely

$$
\frac{\partial \ln L(\theta ; y)}{\partial \mu}=\frac{1}{\sigma^{2}} \sum_{i=1}^{N}\left(y_{i}-\mu\right)=0
$$

Since

$$
\frac{\partial^{2} \ln L(\theta ; y)}{\partial \mu^{2}}=-\frac{N}{\sigma^{2}}<0 \Longrightarrow \text { maximum }
$$

holds, the maximum likelihood estimate for $\mu$ is then obtained by multiplying Eq. (6) with $\sigma^{2}$ and solving for $\hat{\mu}$, which yields

$$
\hat{\mu}_{\mathrm{ML}}=\frac{1}{N} \sum_{i=1}^{N} y_{i}=\bar{y}
$$

\subsubsection{Least Squares Estimator}

Alternatively, one may follow a least-squares approach and construct an estimator that minimizes the $\ell_{2}$ norm, i.e.

$$
\hat{\mu}_{\mathrm{LS}}=\underset{\mu}{\arg \min } d(\mu)=\underset{\mu}{\arg \min } \sum_{i=1}^{N}\left(y_{i}-\mu\right)^{2}
$$


To determine the estimate that minimizes the distance function

$$
d(\mu)=\sum_{i=1}^{N}\left(y_{i}-\mu\right)^{2}=\sum_{i=1}^{N} y_{i}^{2}-2 \mu \sum_{i=1}^{N} y_{i}+N \mu^{2}
$$

one again takes the first derivative and sets it to zero

$$
d^{\prime}(\mu)=-2 \sum_{i=1}^{N} y_{i}+2 N \mu=0
$$

and since

$$
d^{\prime \prime}(\mu)=2 N>0 \Longrightarrow \text { minimum }
$$

holds this yields

$$
\hat{\mu}_{\mathrm{LS}}=\frac{1}{N} \sum_{i=1}^{N} y_{i}=\bar{y}
$$

Thus, if the normality assumption holds, both maximum likelihood and least squares yield the same estimator, in this case the sample mean. Note that this is not generally the case.

\title{
2.2. History of the Normal Distribution and long-held Doubts as to the Validity of the Normality Assumption
}

The optimality of the sample mean (i.e. the arithmetic mean) as an estimate of $\mu$ in Eq. (1) should come as no surprise, for the normal distribution was explicitly invoked by Gauss to justify the use of the arithmetic mean. In fact, in his seminal 1809 work titled "Theoria motus corporum coelestium in sectionibus conicis solem ambientium" (Latin for "Theory of the motion of the heavenly bodies moving about the sun in conic sections"), a contribution to the application of mathematics to astronomy, Gauss provides that

\begin{abstract}
It has been customary certainly to regard as an axiom the hypothesis that if any quantity has been determined by several direct observations, made under the same circumstances and with equal care, the arithmetical mean of the observed values affords the most probable value, if not rigorously, yet very nearly at least, so that it is always most safe to adhere to it. ([2] at 258)
\end{abstract}

Unbeknownst to some, the normal distribution was actually first introduced by Abraham de Moivre in 1733 as a means of approximating the binomial distribution [3,4]. Furthermore, Irish-American mathematician Robert Adrain is believed to have discovered the normal distribution independently of Gauss in 1808, concurrently with his derivation of the method of least squares (the latter however bears striking resemblance to Legendre's derivation) [5].

In his derivation of the normal distribution Gauss built on previous attempts by Laplace to formally justify the use of the sample mean as the optimal estimator for observations contaminated by random errors, an approach customarily used at the time across the entire spectrum of natural sciences despite the lack of formal justification [6]. While by minimizing the absolute value of the estimate's deviation from the true value Laplace failed to prove the optimality of the arithmetic mean he ended up proving the median to be the minimum-variance estimator of the location parameter for the double exponential distribution ${ }^{2}$, whose p.d.f. is given by

$$
f_{Y}(y)=\frac{m}{2} \exp [-m|y-\theta|]
$$

with $0<m<\infty$. Gauss was heavily influenced by Laplace's work and about three decades later finally delivered a formal justification for the use of the sample mean. As Hald (See [6] at 51) emphasizes, but for

2 The double exponential distribution later became known as and today commonly goes by the name of Laplacian distribution. See, e.g. [7] at 6 
the different scaling ( $m / 2$ being replaced by $h / \sqrt{\pi}$ ), Gauss' normal distribution is the double exponential (Laplacian) distribution of Eq. (14) with the exponent $m|y-\theta|$ replaced by $h^{2}(y-\theta)^{2}$ with $h=1 /(\sqrt{2} \sigma)$. Karlgaard remarks that "it is certainly interesting to note that minimum $\ell_{1}$ norm methods based on weighted medians were in use well before the invention of minimum $\ell_{2}$ norm methods" ([7] at 6).

The 'sacredness' of the normality assumption is perhaps best illustrated by the following quote attributed to French physicist Gabriel Lippmann by Poincaré in 1912:

Everyone believes in the normal distribution - Dr. Lippmann once expressed to me - the experimenters because they think that it is a mathematical theorem, and the mathematicians because they think it is an experimental fact. (see, e.g. [8] at 466; [9] at 20)

Thus, the unfoundedness of the normality assumption had clearly been known long before the advent of the contemporary formal field of robust statistics (see Section 2.3). This is relevant, for it has a direct and profound impact on notions such as negligence, duty of care, and perhaps most importantly, the state of scientific and technical knowledge, as shall be discussed in Section ??. Evidence shows that, despite its widespread use and acceptance, the normality assumption has been disputed by respected scholars since the first 19th century. For instance, back in 1818 Bessel in an empirical analysis of the measurement errors of astronomical observations noted that they did in fact not follow Gauss' normal distribution [7,10].

\subsection{Contemporary Robustness Theory: Tukey, Huber and Hampel}

The contemporary notion and use of the term 'robustness' was coined by George Box in his 1953 Biometrika paper [11]. The advent of the contemporary field of robust statistics is however inextricably bound to John W. Tukey, Peter J. Huber and Frank R. Hampel (in that order) $[12,13]$.

\subsubsection{Tukey's 1960 Paper}

Tukey in 1960 [14] famously drew broad attention to the fact that, when contaminating the normal distribution with varying percentages $\epsilon$ of a slightly heavier tailed distribution (in Tukey's example a normal distribution with its standard deviation increased by a factor of 3 ), it takes less than $1 \%$ of contamination to "utterly destroy the average performance of so-called optimal estimators." ([15] at 272)

Given some observations $x_{i}$

$$
x_{i} \sim(1-\epsilon) \mathcal{N}\left(0, \sigma^{2}\right)+\epsilon \mathcal{N}\left(0,9 \sigma^{2}\right)
$$

the sample standard deviation (or root mean square deviation)

$$
s_{n}=\left[\frac{1}{n} \sum\left(x_{i}-\bar{x}\right)^{2}\right]^{1 / 2}
$$

and the mean deviation (or mean absolute deviation)

$$
d_{n}=\frac{1}{n} \sum\left|x_{i}-\bar{x}\right|
$$

can be used as scale estimators. It turns out, however, that as soon as one contaminates the distribution of $x_{i}$ in Eq. (15) with a fraction as tiny as $\epsilon=0.0018$ from the heavier tailed distribution, the root mean square deviation ceases to be more efficient than the mean absolute deviation and at $\epsilon=0.05$ the latter is twice as efficient as the former (see [16] at 6). This holds for all $0.002 \leq \epsilon \leq 0.5$ (see [17,18] at 3; see also [16]) and stands to exemplify that classical procedures are highly susceptible to even tiny deviations from the assumed model. In other words, they are not distributionally robust. 


\subsubsection{Huber's 1964 Minimax Approach}

Huber's 1964 groundbreaking paper [19] on the 'Robust Estimation of a Location Parameter' is commonly agreed upon as the first formal and solid contribution to the modern theory of robust statistics. In said paper, Huber depicts the task of constructing a robust location estimator as a zero-sum game between nature and the statistician, wherein nature chooses a distribution in the neighborhood of the assumed model followed by the statistician's choice of an appropriate estimator which minimizes the asymptotic variance for the worst possible case the considered neighborhood of the model allows. The neighborhood is described by the gross error or $\epsilon$-contamination model for contaminated normal distributions where a fraction $\epsilon$ of the data stems from a contaminating distribution, as already encountered in Eq. (15) where the contaminating distribution is $\mathcal{N}\left(0,9 \sigma^{2}\right)$. Huber solves the posed minimax problem by introducing a new class of asymptotically normal and consistent generalized maximum likelihood estimators, called M-estimators.

As previously discussed in Section 2.1.1, the maximum likelihood estimate is obtained by solving for the value that maximizes the log-likelihood function of the data, i.e. given observations $x_{1}, \ldots, x_{N}$ from the corresponding density $f_{X}(x ; \mu)$ one obtains $\hat{\mu}_{\mathrm{ML}}$ as

$$
\hat{\mu}_{\mathrm{ML}}=\underset{\mu}{\arg \max } \sum_{i=1}^{N} \ln f_{X}\left(x_{i} ; \mu\right)
$$

or equivalently by solving

$$
\sum_{i=1}^{N} \frac{\partial \ln f_{X}\left(x_{i} ; \mu\right)}{\partial \mu}=0
$$

Huber generalizes this by instead solving

$$
\hat{\mu}_{\mathrm{M}}=\underset{\mu}{\arg \min } \sum_{i=1}^{N} \rho\left(x_{i}-\mu\right)
$$

or equivalently by solving

$$
\sum_{i=1}^{N} \psi\left(x_{i}-\hat{\mu}_{\mathrm{M}}\right)=0
$$

with $\psi=\rho^{\prime}$ being the score-function. Note that while choosing $\rho=-\ln f_{X}(x)$ and $\psi=-f_{X}(x)^{\prime} / f_{X}(x)$ yields the maximum likelihood estimator as a particular case of the M-estimator, the latter is more general in that the score function $\psi$ is not required to be the derivative of some $\rho$-function with respect to the parameter of interest. An important $\rho$-function is the so-called Huber $\rho$-function

$$
\rho(x)= \begin{cases}\frac{1}{2} x^{2} & |x| \leq c_{\text {Hub }} \\ c_{\text {Hub }}|x|-\frac{1}{2} c_{\text {Hub }}^{2} & |x|>c_{\text {Hub }}\end{cases}
$$

with the corresponding $\psi$-function

$$
\psi(x)= \begin{cases}x & |x| \leq c_{\mathrm{Hub}} \\ c_{\mathrm{Hub}} \operatorname{sign}(x) & |x|>c_{\mathrm{Hub}}\end{cases}
$$

Note that the limit cases of $c_{\text {Hub }} \rightarrow \infty$ and $c_{\text {Hub }} \rightarrow 0$ correspond to the sample mean and the sample median, respectively. Accordingly, $\hat{\mu}_{M}$ represents an intermediate between mean and median [19-21]. In simple cases, such as the one-dimensional location estimation considered here, the aforementioned game between nature and the statistician has an explicit asymptotic minimax solution. In fact, the M-estimator of Eq. (22) is the maximum likelihood estimator corresponding to a unique least favorable distribution with density

$$
f_{0}(x)=(1-\epsilon)(2 \pi)^{-\frac{1}{2}} \exp [-\rho(x)]
$$


which behaves like a normal distribution for small $x$ and like an exponential distribution for larger values of $x$ (see, e.g. $[13,17,19])$.

Comparing ML and M estimators, the crucial difference is that $\rho_{\mathrm{ML}}=-\ln f_{X}(x)$ and $\psi_{\mathrm{ML}}=-f_{X}(x)^{\prime} / f_{X}(x)$ are unbounded while $\rho_{\mathrm{M}}$ is quadratic in the middle and linear in the tails resulting in a score function $\psi_{\mathrm{M}}$ bounded by $c_{\text {Hub }}$ where $1.0 \leq c_{\text {Hub }} \leq 2.0$ will give acceptable results for all $\epsilon \leq 0.2$ (see [19] at 82). A commonly used value is $c_{\text {Hub }}=1.345$. It is in fact the boundedness of $\psi$ which makes the M-estimator robust [13,17,19-21].

\subsubsection{Hampel's Infinitesimal Approach}

An intuitive approach to assess the influence of an arbitrary data point $x$ on a statistic computed on a sample was proposed by Tukey [22] in form of the sensitivity curve (SC). Given a sample $x_{1}, \ldots, x_{n-1}$ drawn from $\mathcal{N}\left(0, \sigma^{2}\right)$ by adding an additional arbitrary data point $x$ the sensitivity curve for the sample mean $\bar{x}_{n}=\frac{1}{n} \sum_{i=1}^{n} x_{i}$ is

$$
S C_{n}(x)=\frac{\left(x_{1}+x_{2}+\cdots+x\right) / n-\bar{x}_{n-1}}{1 / n}=x-\bar{x}_{n-1}
$$

a linear function in $x$ (see [20] at 17). The limit of $S C_{n}(x)$ for $n \rightarrow \infty$ then represents the asymptotic influence of the additional arbitrary data point $x$ on the sample mean. $S C_{n}(x)$ however is generally sample-dependent (see [20] at 17). Hampel in his $1968 \mathrm{Ph} . D$. thesis [23] and 1974 paper [24] introduced a more versatile notion in form of the influence function (IF), broadening the SC to more general types of estimators through the use of functionals.

Let $F_{n}$ denote the empirical distribution function of the sample $x_{1}, \ldots, x_{n}$ and $\hat{\theta}=\left(x_{1}+\cdots+x_{n}\right) / n$ the sample mean. Expressed as functional this would be $\hat{\theta}\left(F_{n}\right)=\int x d F_{n}(x)$. Hampel's IF is defined as

$$
I F(x, \hat{\theta}, F)=\lim _{\epsilon \rightarrow 0} \frac{\hat{\theta}\left((1-\epsilon) F+\epsilon \Delta_{x}\right)-\hat{\theta}(F)}{\epsilon}
$$

where $\Delta_{x}$ denotes point-mass 1 at $x$. That is, the IF expresses the difference of the estimator following the contaminated distribution and the estimator following the nominal (uncontaminated) distribution standardized by the fraction of contamination as said fraction of contamination goes to zero. For M-estimators the influence function is proportional to the defining $\psi$-function. Hampel showed that

$$
\operatorname{bias}(\epsilon, \hat{\theta}, F) \simeq \epsilon \sup _{x}|I F(x, \hat{\theta}, F)|
$$

i.e. the asymptotic bias of an estimator with bounded influence function is bounded as well (see, e.g. [9] at $176 ;[20]$ at 18).

\subsubsection{The Breakdown Point}

An important 'limitation' of Hampel's influence function is that it only describes the local stability of an estimator (or, more technically, "the infinitesimal stability of (the asymptotic value of) an estimator" [9] at 96). Accordingly, as Hampel points out in the same paragraph, "it must be complemented by a measure of the global reliability of the estimator, which describes up to what distance from the model distribution the estimator still gives some relevant information.” The Breakdown Point (BP) is one - and by any means the most popular and best comprehensible - such measure. Loosely speaking, the breakdown point provides the minimum amount of contamination necessary for the estimator to produce arbitrarily large changes to the estimate. Put differently, it is the maximum amount of contamination an estimator can withstand before it breaks down, i.e. before its bias becomes arbitrarily large. Apparently then the breakdown point can take any value between 0 and 0.5 , for beyond $50 \%$ contamination it is no longer possible to differentiate between the nominal and the contaminating distribution(s). It shall be noted though that despite its apparent tangibility, the BP is subject to some controversy in the statistical literature (see, e.g. [25]). 
The asymptotic breakdown point (ABP) $\epsilon^{*}$ of a sequence of estimators $T_{n}$ for parameter $\theta \in \Theta$ at probability $F$ is defined by

$$
\epsilon^{*}:=\sup \left\{\epsilon \leq 1 \text {; there is a compact set } K_{\epsilon} \varsubsetneqq \Theta \text { s.t. } \pi(F, G)<\epsilon \Longrightarrow G\left(\left\{T_{n} \in K_{\epsilon}\right\}\right) \stackrel{n \rightarrow \infty}{\longrightarrow} 1\right\}
$$

with $\pi$ being the Prohorov distance (see [9] at 97).

The finite sample breakdown point (FSBP) $\epsilon_{n}^{*}$ of the estimator $T_{n}$ at sample $\left(x_{1}, \ldots, x_{n}\right)$ is given by

$$
\epsilon_{n}^{*}\left(T_{n} ; x_{1}, \ldots, x_{n}\right):=\frac{1}{n} \max \left\{m ; \max _{i_{1}, \ldots, i_{m}} \sup _{y_{1}, \ldots, y_{m}}\left|T_{n}\left(z_{1}, \ldots, z_{n}\right)\right|<\infty\right\}
$$

where the sample $\left(z_{1}, \ldots, z_{n}\right)$ is obtained by replacing the $m$ data points $x_{i_{1}}, \ldots, x_{i_{m}}$ by the arbitrary values $y_{1}, \ldots, y_{m}$ (see [9] at 98). In many cases, taking $\lim _{n \rightarrow \infty} \epsilon_{n}^{*}$ yields the ABP $\epsilon^{*}$.

It is worth noting that the FSBP of Eq. (29) differs from the one proposed by Donoho and Huber [26] in that, e.g., the latter yields $1 / n$ for the sample mean whereas the FSBP of Eq. (29) yields 0. This is due to Donoho and Huber taking the smallest $m$ for which the maximum supremum of $\left|T_{n}\left(z_{1}, \ldots, z_{n}\right)\right|$ is infinite, resulting in their FSBP yielding $\epsilon_{n}^{*}+1 / n$ (again, see [9] at 98).

\subsection{Nonparametric Statistics}

The limited ability to adequately represent real-world circumstances is a drawback inherent to all low-dimensional parametric models, a fact which is nicely illustrated by Härdle's analogy to the Greek mythological figure of Procrustes ${ }^{3}$. Somewhat paraphrasing Härdle, one may think of the conventional parametric modeling approach as akin to projecting the observed data onto a Procrustean bed of fixed parametrization, recklessly disregarding that "the preselected parametric model might be too restricted or too low-dimensional to fit unexpected features" ([27] at 5). Accordingly, switching the normal distribution for another low-dimensional parametric probability distribution would in essence be akin to Procrustes switching to his alternative torture bed, shifting and perhaps slightly ameliorating the problem, yet remaining far from reaching a more universally acceptable solution.

\subsubsection{Clearing up Some Definitions}

Labels such as 'robust', 'nonparametric' and 'distribution/model free' are not as clearly defined as one might expect, which has led to rather frequent ambiguities and misclassifications (see, e.g. [18] at 6-7). The following classification therefore appears in order:

- $\quad$ Robust Procedures are essentially parametric procedures that have been "hardened" so as to allow for (small) deviations from the assumed nominal model. At their core, however, they remain parametric methods, i.e. they are based on the explicit or implicit assumption of a clearly defined model which is fully described by a rather low-dimensional set of parameters (e.g. $[\mu, \sigma]$ for the normal distribution).

- $\quad$ Nonparametric Procedures on the other hand are different in that no such restrictive assumptions are made. In fact, one may interpret nonparametric statistics as being 'infinitely dimensional parametric'. However, certain assumptions are commonly encountered in nonparametric statistics as well, e.g. that the data sample

3 Procrustes ('the stretcher'), was a Greek robber who would lure unsuspecting travelers into his house by promising them a nice meal and a comfortable bed to spend the night. Procrustes then proceeded to have his victims lie on his special (torture) bed, which he obsessively wanted to be the perfect fit for his victims. Since it virtually never was, Procrustes would accordingly 'adjust' his victims so to as to achieve a perfect fit. This meant that, if they were too short, they would be stretched while if they were too big, they would have their extremities cut off. Procrustes is purported to actually have had two such beds of slightly different dimensions to account for the unlikely case that a victim would fit the first bed perfectly. See, e.g. 'Procrustes', Encyclopaedia Britannica, https://www.britannica.com/topic/Procrustes, n.d. Web. May 15, 2017. 
is a sequence of independent and identically distributed (i.i.d.) random variables and/or that the set of possible probability densities be restricted to symmetric ones.

- Distribution-free Procedures are test statistics whose null distribution does not depend on the probability distribution from which the sample was drawn, i.e. the sampling distribution under the null is the same for all possible underlying distributions. Estimates derived from such tests are also commonly referred to as distribution-free, even though this is generally not true (see, e.g. [18] at 6-7). Nevertheless, the terms 'nonparametric' and 'distribution-free' are often used interchangeably (see, e.g. [28] at 114).

\subsubsection{Some Basic Nonparametric Procedures}

Nonparametric procedures often rely on rank transformation of the data, i.e. the observed data points are replaced by their respective ranks. Even more basic is the sign-test proposed by Arbuthnot [29] back in 1710 to refute the claim that newborns were equally likely to be male and female [30,31]. Given $n$ observations from a population which may be discrete or continuous and need not be symmetric, one hypothesizes that the median under the null be, say $M_{0}$ and then counts the number of observations exceeding $M_{0}$. The null and the alternative both follow a binomial distribution and if $H_{0}: M=M_{0}$ holds, the number of values smaller than $M_{0}$ will have a binomial distribution with parameters $n$ and $p=0.5$ and the counted number of observations greater than $M_{0}$ may then be used as an alternative equivalent statistic in a one or two-tail test (see, e.g. [30], p. 1316). While the basic sign-test is neither particularly efficient nor powerful, it shall be emphasized that it does not assume a symmetric population.

Arguably however, the advent of the modern era of nonparametric tests can be traced back to seminal contributions by Wilcoxon [32] in 1945, Mann and Whitney [33] in 1947, and Hodges and Lehmann [34] in 1956. Specifically, Wilcoxon proposed the Wilcoxon signed rank test for medians of symmetric distributions and the Wilcoxon rank sum test for the difference in medians and Mann and Whitney showed the rank sum test to be equivalent to the sign-test for pairwise differences across the two samples while Tukey in 1949 showed that the Wilcoxon signed rank test is equivalent to the sign test when applied to pairwise averages from the samples, which Tukey referred to as Walsh-averages (see, e.g. [31] at 2). Hodges and Lehmann [34] showed that the asymptotic relative efficiency (ARE) of the Wilcoxon tests compared to t-tests is $>0.864$. Specifically, the ARE is $3 / \pi=0.955$ at the normal and has in general no upper limit $[30,31]$.

For the sake of brevity and for better comparison to robust procedures discussed earlier, the discussion of nonparametric procedures in this Section shall be limited to R-estimators. For a in depth appraisal the reader is referred to, e.g. [28,35-37].

\subsubsection{R-Estimators}

Roughly speaking, procedures based on rank statistics require less restrictive assumptions regarding the underlying distribution and are inherently robust against distributional departures such as misspecified models, contamination and outliers. Furthermore, these inherent robust properties are generally globally robust as opposed to conventional robust statistics (e.g. M-estimators) which are rather locally robust (see, e.g. [37] at 91).

In their seminal 1963 paper [38] Hodges and Lehmann built on the prior art by Wilcoxon, Tukey, Mann, and Whitney outlined in Section 2.4.2 and proposed a class of robust estimators based on rank tests commonly referred to as R-estimators. Most importantly, they were able to show that these estimators inherit the desirable robustness and efficiency aspects of the rank tests they are based on. While originally being derived from one-sample tests ( $c f$. [38]), it has become more customary to introduce them following an approach based on two-sample test (see, e.g. [9,17]). Below the derivation found in [17] will be followed.

Consider two independent samples $\left(x_{1}, \ldots, x_{m}\right) \sim F(x)$ and $\left(y_{1}, \ldots, y_{n}\right) \sim G(x)$ with $G(x)=F(x-\Delta)$, i.e. with $G(x)$ equal to $F(x)$ but for an unknown location shift $\Delta$. Let the two samples be merged into a sample of size $m+n$ and let $R_{i}$ represent the rank of $x_{i}$ in said merged sample. Let furthermore $a_{i}=a(i)$ with 
$1 \leq i \leq m+n$ be some given scores (weights). One may then test for $\Delta=0$ against $\Delta>0$ based on the test statistic

$$
S_{m, n}=\frac{1}{m} \sum_{i=1}^{m} a\left(R_{i}\right)
$$

with scores $a_{i}$ generated by some function $J$

$$
a_{i}=(m+n) \int_{(i-1) /(m+n)}^{i /(m+n)} J(s) d s
$$

with

$$
\int J(s) d s=0
$$

and accordingly

$$
\sum a_{i}=0
$$

Under the null hypothesis of $\Delta=0$ the expected value of Eq. (30) is then 0 .

In the following, let $m=n$ for the sake of simplicity. Eq. (30) expressed in terms of functionals reads as

$$
S(F, G)=\int J\left[\frac{1}{2} F(x)+\frac{1}{2} G(x)\right] F(d x)
$$

and by substituting $F(x)=s$

$$
S(F, G)=\int J\left[\frac{1}{2} s+\frac{1}{2} G\left(F^{-1}(s)\right)\right] d s
$$

Note how Eq. (35) together with Eq. (31) yields Eq. (30).

An R-estimator of location $T_{n}$ and shift $\Delta_{n}$ can be derived by adjusting $\Delta_{n}$ such that Eq. (30) computed for samples $\left(x_{1}, \ldots, x_{n}\right)$ and $\left(y_{1}-\Delta_{n}, \ldots, y_{n}-\Delta_{n}\right)$ becomes as close to zero as possible, i.e. $S_{n, n} \approx 0$. In the one-sample case one adjusts $T_{N}$ such that $S_{n, n} \approx 0$ when computed for samples $\left(x_{1}, \ldots, x_{n}\right)$ and $\left(2 T_{n}-x_{1}, \ldots, 2 T_{n}-x_{n}\right)$, i.e. the missing second sample is replaced by a mirror image of the first sample wherein each $x_{i}$ is replaced by $T_{n}-\left(x_{i}-T_{n}\right)=2 T_{n}-x_{i}$. Put differently, $S_{n, n} \approx 0$ means that one adjusts or rather shifts the second sample, either through $\Delta_{n}$ in the two-sample case or $T_{n}$ in the one-sample case, such that a difference between the two is no longer discernible.

The location estimator $T_{n}$ thus derives from a functional $T(F)$, defined by the implicit equation

$$
\int J\left\{\frac{1}{2}\left[s+1-F\left(2 T(F)-F^{-1}(s)\right)\right]\right\} d s=0
$$

(see, e.g. [17] at 62; [9] at 111).

The Wilcoxon test, $J(t)=t-\frac{1}{2}$ e.g. yields the Hodges-Lehmann estimates $\Delta_{n}=\operatorname{med}\left\{y_{i}-x_{j}\right\}$ and $T_{n}=\operatorname{med}\left\{\frac{1}{2}\left(x_{i}+x_{j}\right)\right\}$

The score generating function $J(t)$ shall be assumed to be symmetric, i.e.

$$
J(1-t)=-J(t), \quad 0<t<1
$$


and a function $U(x)$ shall be introduced as the indefinite integral of

$$
U^{\prime}(x)=J^{\prime}\left\{\frac{1}{2}[F(x)+1-F(2 T(F)-x)]\right\} f(2 T(F)-x) .
$$

The influence function of the R-estimator can then be shown to be

$$
I F(x ; F, T)=\frac{U(x)-\int U(x) f(x) d x}{\int U^{\prime}(x) f(x) d x}
$$

which for symmetric $F$, which in turn implies $U(x)=J(F(x))$, simplifies to

$$
I F(x ; F, T)=\frac{J(F(x))}{\int J^{\prime}(F(x)) f(x)^{2} d x}
$$

(see [17], Section 3.4).

For a monotone and integrable $J$ for which $T(F)$ is uniquely defined, $T$ is continuous at $F$ and the breakdown point $\epsilon^{*}$ is given the value of $\epsilon$ for which

$$
\int_{1 / 2}^{1-\epsilon / 2} J(s) d s=\int_{1-\epsilon / 2}^{1} J(s) d s
$$

(see, e.g. [17] at 67; [9] at 112).

Accordingly, the Hodges-Lehmann estimator of location $J(t)=t-\frac{1}{2}$, i.e. the median of pairwise averages, has a breakdown point of

$$
\epsilon^{*}=1-\frac{1}{\sqrt{2}} \approx 0.293
$$

which is to be considered reasonably high.

\section{Civil Liability for Product Defects}

In the following the distinct mechanisms and ramifications arising from the three main liability constructs, which are depicted in Table 2, will be analyzed and necessary and up-to-date references to case law to interpret and apply them correctly will be provided. In doing so, a self-contained and concise, yet exhaustive picture of these extensive areas of civil law is developed, thereby removing the requirement of prior knowledge of the subject matter on the part of the reader. In essence, all statutory provisions of relevance to the discussions

Table 2. Overview of the three main liability constructs for defective products

\section{Liability for defective products}

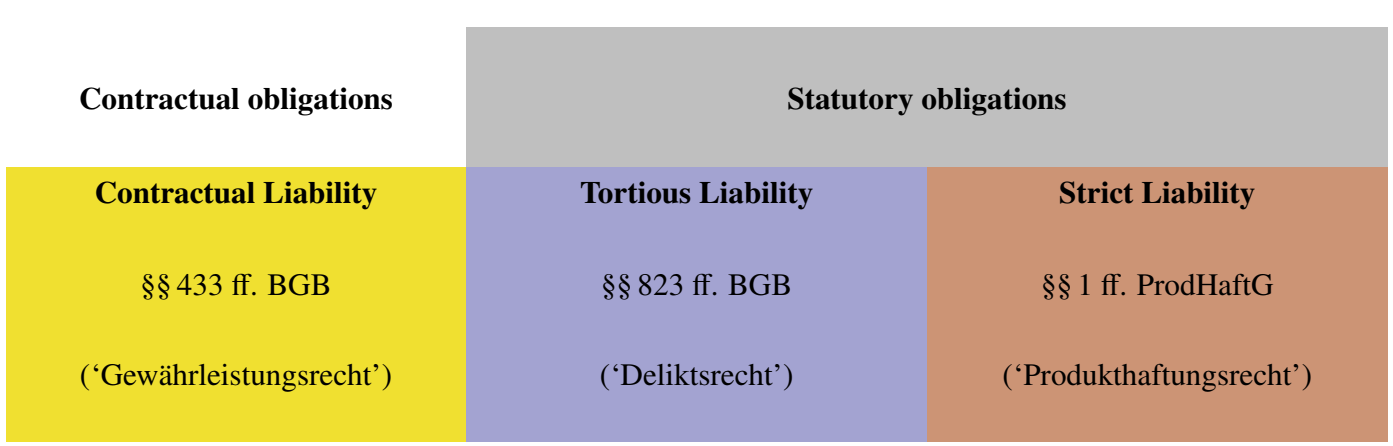

in this work are those of the special part of the law of obligations ('Schuldrecht - Besonderer Teil') and the Product Liability Act ('Produkthaftungsgesetz'). There is however a caveat to that. For these sections are not 
self-contained but have to be interpreted in the broader context of the code due to provisions included by reference. It will be shown that these distinct liability constructs are not mutually exclusive, but coexist and can be applied in parallel. An awareness and understanding of these liability mechanisms is therefore of paramount importance and ought to be incorporated into and influence all stages of research, product design and development.

\subsection{Contractual Liability}

Civil liability for product defects is part of the law of obligations where in turn a fundamental distinction between contractual obligations ('vertragliche Haftung') and statutory obligations ('gesetzliche Haftung') shall be made. The former, as the term implies, requires a contractual relationship between the parties while the latter covers faulty conduct ('Verschuldenshaftung') as well as strict (as for there is no fault requirement) liability ('Gefährdungshaftung')

Thus, before discussing the arguably more important matters of tortious product liability ('deliktische Produzentenhaftung') and strict product liability ('Produkthaftung nach ProdHaftG') attention shall briefly be directed to contractual liability.

\subsubsection{Requirements}

For a contractual liability to attach the prerequisite of the existence of a valid sales contract between buyer and seller has to be satisfied. Depending on whether the relationship is "Business to Consumer" (B2C) or "Business to Business" (B2B) laws pertaining to purchase agreements ('Kaufvertragsrecht') or to contracts to produce a work ('Werkvertragsrecht') apply, for the B2C and B2B scenarios, respectively. Typical contractual duties in a purchase agreement are listed in $\S 433$ BGB and in $\S 631$ BGB for a contract to produce a work.

\subsubsection{Material and Legal Defects}

$\S 433$ I 2 BGB states that the seller must procure the thing for the buyer free from material and legal defects. It shall be emphasized that in this context the term defect is subject to a wide interpretation. As one would expect, §434 I 1 BGB states that in order to be considered free of material defects the thing, upon the passing of risk ('Gefahrenübergang'), has to be of the agreed quality. The legislator's broad interpretation of the term defect however becomes apparent in § 434 I 2 BGB which specifies that, in case the quality has not clearly been articulated in the respective contractual agreement, the thing has to be suitable for the use intended under the contract ( $\$ 434$ I 2 No. 1 BGB) or it has to be suitable for the customary use and of the quality a reasonable buyer would expect from a product of this kind ( $\$ 434$ I 2 No. 2 BGB). The legislator goes on to further clarify that quality under $\S 434$ I 2 No. 2 BGB includes expectations reasonably induced in the buyer by advertisement or public statements concerning product characteristics made by the seller, the producer or vicarious agents of either one ( $\$ 434$ I 3 BGB).

The product, on the other hand, is considered free of 'legal defect' if pertaining to the purchase third parties can either assert no rights at all or only assert such rights appropriated by the buyer in the underlying contractual agreement ( $\$ 435$ BGB) Klindt et al. [39] provide the example of a software that was sold even though it incorporates and uses proprietary libraries without the appropriate license. This would constitute a textbook example of a 'legal defect' of the product as the rights holder may bring actions against the buyer of said software product.

For B2B scenarios the notion of material and legal defect is defined analogously in $\S 633$ BGB. For the sake of brevity the following discussion will mainly consider B2C scenarios.

\subsubsection{The Special Case of Software}

Even though the legal community widely accepts the fact that due to the intrinsically complex nature of software products an absolute absence of material defects cannot be achieved according to the prevailing opinion this shall not justify a deviation from the generally accepted and above stated definitions of what constitutes a 
product defect ${ }^{4}$. In a 2006 landmark decision ${ }^{5}$ the BGH, among other things, found software to be a thing in terms of $\S 90$ BGB for which depending on whether the goods were surrendered subject to a purchase or a lease agreement sales or tenancy laws are to be applied, respectively. Note that $\S 90$ BGB states that only corporeal objects are things as defined by law, a definition that at first sight would exclude software products. However the court argued that for the software to be of any actual use it necessarily had to be materialized on some sort of storage medium thereby satisfying the corporeal object requirement. This is consistent with previous BGH decisions regarding the composition of software ${ }^{6}$.

\subsubsection{Legal consequences of defects}

The rights granted by the legislator to the buyer of a defective product are manifold (see, e.g. [40] for an exhaustive discussion of the matter).

\section{$\S 437$ BGB states that the buyer may:}

1. demand cure under $\S 439$ BGB

2. revoke the purchase under $\S \S 440,323,326$ V BGB

3. reduce the purchase price under $\$ 441 \mathrm{BGB}$

4. demand damages under $\S \S 440,280-283,311$ a BGB

5. demand reimbursement of futile expenses under $§ 284$ BGB

\subsubsection{Boundaries on the Exclusion of Contractual Liability}

In light of the above considerations it may appear tempting to exclude or limit liability by resorting to contractual provisions. However, the legislator imposed strict boundaries on such practices. Generally speaking, as far as contracts go, the crucial distinction to keep in mind is between individually negotiated terms of contract ('Individualvertrag') on one hand and general terms and conditions ('Allgemeine Geschäftsbedingungen' - AGB) on the other hand. While the legislator imposes relatively few and very basic boundaries on the former (e.g. violation of morality ('Sittenwidrigkeit') as in $\S 138$ BGB), the latter are heavily regulated ( $\S 305 \mathrm{ff}$. BGB). $\S 305$ I 1-2 BGB define general terms and conditions as

all contract terms pre-formulated for more than two contracts which one party to the contract (the user) presents to the other party upon the entering into of the contract. It is irrelevant whether the provisions take the form of a physically separate part of a contract or are made part of the contractual document itself, what their volume is, what typeface or font is used for them and what form the contract takes.

Clearly, in practice the vast majority of contracts will fall into this category. On the other hand, contract terms do not become standard business terms to the extent that they have been negotiated in detail between the parties ( $\$ 305$ I 3 BGB) and individually agreed terms take priority over standard business terms ( $3305 \mathrm{~b}$ BGB). Caution is required though due to the BGH's very strict interpretation of what does and does not constitute a valid negotiation for the sake of eventually obtaining a valid individual contractual agreement. In fact, according to consistent decisions by the BGH merely 'negotiating' contractual provisions does not suffice, rather an act of bargaining is required ${ }^{7}$.

For general terms and conditions to be validly incorporated the contracting party needs to acknowledge and agree to them ( $\$ 305$ II BGB). Surprising and ambiguous clauses are void by law ( $\$ 305$ c I BGB) and if doubts in the interpretation arise they are resolved against the user of the pre-formulated terms and conditions ( $\$ 305 \mathrm{c}$ II BGB). 
The rules in $\S \S 305 \mathrm{ff}$. BGB apply regardless of possible attempts to circumvent them by other constructions (§306a BGB). The legislator severely limits the user's ability to exclude liability. According to §307 I BGB provisions are ineffective if, contrary to the requirement of good faith, they unreasonably disadvantage the other party to the contract with the user. An unreasonable disadvantage may also arise from the provision not being clear and comprehensible. Furthermore, $\S 309$ BGB explicitly forbids the exclusion of liability for injury to life, body or health and in case of gross fault ( $\$ 309$ No. 7 BGB) as well as other exclusions of liability for breaches of duty ( $\$ 309$ No. 8 BGB) - of particular relevance here those pertaining to defects in contracts relating to the supply of newly produced things and relating to the performance of work where provisions excluding liability for defects overall or in regard to individual parts are void by law as are those limiting to the granting of claims against third parties or made dependent upon prior court actions ( $\$ 309$ No. 8 aa) BGB). It is also worth mentioning that the recent addition of $\S 309$ No. 14 to the German Civil Code specifies that provisions mandating an attempt of Alternative Dispute Resolution (ADR) to have been undertaken and failed prior to the filing of a claim against the user are also explicitly forbidden ${ }^{8}$.

\subsection{Tortious Product Liability}

We can think of the special part of the law of obligations ('Schuldrecht Besonderer Teil') as having two main pillars:

(i) 'contractual obligations' ('vertragliche Schuldverhältnisse')

(ii) 'statutory obligations' ('gesetzliche Schuldverhältnisse')

of particular relevance to the matter at hand, the 'law of unlawful actions' ('Recht der unerlaubten Handlungen' or 'Deliktsrecht')

While implications of the former were discussed in the previous section, in this section the focus will be on the latter, also known as 'the law of torts'. Broadly speaking, a tort is a civil wrong other than a breach of contract for which damages can be recovered.

\subsubsection{The German Law of Torts, §§ 823-853 BGB}

There are three 'general provisions' in the German law of torts, namely §§ 823 I, 823 II and 826 BGB, of which $\S 823 \mathrm{I}$ is generally regarded as being the most significant. The sections read as follows:

\section{$\S 823$}

(1) A person who, intentionally or negligently, unlawfully injures the life, body, health, freedom, property or another right of another person is liable to make compensation to the other party for the damage arising from this.

(2) The same duty is held by a person who commits a breach of a statute that is intended to protect another person. If, according to the contents of the statute, it may also be breached without fault, then liability to compensation only exists in the case of fault.

$\S 826$

A person who, in a manner contrary to public policy, intentionally inflicts damage on another person is liable to the other person to make compensation for the damage.

Contrary to specific product liability acts, the delict provisions of the BGB, i.e. $\S \S 823-853$, are not specifically intended to address product liability matters but are general tools for the claimant to seek compensation for damages that arose from the infringement of one or multiple of the claimant's absolute rights by a tortfeasor's faulty conduct. 'Absolute rights' are 'erga omnes' (Latin for 'towards all') rights, i.e. "rights which can be interfered with by everyone and which can be asserted against everyone" ([41], p. 69). In contrast, "relative

$8 \S 309$ No. 14 BGB as introduced by the amendment of the German Civil Code, effective February 26th, 2016, cf. BGB1 I Nr. 9/2016, S. $254 \mathrm{ff}$. 
rights' would be rights that can only be asserted on the basis of an existing legal relationship, e.g. rights that can be asserted by one party against other parties it has entered into a binding contractual agreement with.

$\S 823 \mathrm{I}$ and $\S 823 \mathrm{II}$ are by far the most relevant delict provisions pertaining to product liability matters. Of minor importance is $\S 826$, which is distinct in that it allows for the recovery of purely economic loss, provided that the damage was inflicted intentionally (i.e. willfully and 'not just negligently') and "in a manner contra bonos mores" ([41] at 15). The recovery of purely economic loss is not possible under $\S 823$ I but it is under $\S 823$ II. The actual applicability of $\S 826$ compared to $\S \S 823$ I,II is severely limited by factual prerequisites of an intentional infliction that furthermore has to be contra bonos mores.

\subsubsection{Fault-based Product Liability under Tort Law}

$\S 823$ I BGB provides that damages arising from the intentional or negligent, unlawful injury to life, body, health, freedom, property or other absolute rights of another person are to be compensated by the wrongdoer.

We point out that

1. The statute is applicable only to infringements committed by a person (physical or legal) to the detriment of another person's rights or interests, provided they are one of the rights or interests explicitly listed by the statute or included by reference to the person's 'other (absolute) rights', as discussed earlier.

2. No contractual or semi-contractual relationship between the parties is required.

3. Damages must arise from the wrongdoers faulty conduct ('Verschuldenshaftung'), i.e. the conduct has to be willful/intentional ('vorsätzlich') ${ }^{9}$ or negligent ('fahrlässig') ${ }^{10}$.

4. The conduct must furthermore be unlawful. According to the prevailing opinion this requirement is regularly met whenever a person's absolute rights are infringed absent a legally recognized justification ('Rechtfertigungsgrund').

5. There must be an adequate causal link between the claimant's damages and the defendant's conduct, either through an active act ('Aktives Tun') or through an act of omission ('Unterlassen').

Liability arising from acts of omissions evidently deserve careful consideration in the area of products liability. For it may be argued that in the ordinary course of events, an infringement of protected rights or interests by the manufacturer due to negligent or intentional omission is more likely than due to active wrongdoing. This leads us to the central notion of duty of care (Verkehrssicherungspflicht) pertaining to $\S 823 \mathrm{I}$.

\subsubsection{Duty of Care ( $\$ 823$ I BGB)}

The following duties of care have been established by German case law

\section{Liability for defective design ('Konstruktionsfehler')}

The manufacturer has to design the product such that to his best abilities and under reasonable economic feasibility constraints, no unreasonably unsafe or dangerous product with respect to the current scientific and technological knowledge will be placed on the market. The manufacturer is also expected to anticipate and take into account the (potentially improper) use of its product outside the intended scope and by users other than those it was originally intended for and marketed to if he knew or ought to have known that such scenarios were conceivable.

2. Liability for defects in manufacture ('Fabrikationsfehler')

9 The definition of intention and negligence is provided by $\S 276 \mathrm{BGB}$ which states that the obligor is responsible for intention and negligence, if a higher or lower degree of liability is neither laid down nor to be inferred from the other subject matter of the obligation, including but not limited to the giving of a guarantee or the assumption of a procurement risk. The provisions of $\S 827$ and $\S 828$ apply with the necessary modifications. ( $\$ 276$ I BGB)

10 A person acts negligently if he fails to exercise reasonable care. (\$276 II BGB) 
Presuming the absence of design defects, defective products may still result from irregularities in the manufacturing process itself, e.g. due to human error or defective machinery. To address this, adequate quality control measures and policies must be implemented and enforced to ensure the adherence to established quality and safety standards. It is evident though that defects of individual products can never be completely avoided, despite all quality control mechanisms and safeguards.

In this context it is important to emphasize that the manufacturer is not liable for 'outliers' ('Ausreißer'), i.e. single defective products, provided he undertook reasonable and adequate efforts to avoid them or at least to detect them and hinder the afflicted products from leaving the manufacturer's 'sphere of control'. As shall be explained in Section 3.3, the 'outlier-defense' can however only be invoked to exculpate oneself from tortious liability whereas the manufacturer will still be held strictly liable under ProdHaftG.

\section{Liability for defective instruction ('Instruktionsfehler')}

The manufacturer is obliged to clearly warn from dangers arising from the use of its product, especially if used as intended and if the danger is not immediately discernible. Depending on the level of danger and the foreseeability of misuse or improper use giving rise to said danger, the duty to make users aware may also expand to encompass use cases outside the product's intended use.

Warnings have to be articulated clearly and unambiguously and, depending on the severity of the danger, be further emphasized and highlighted. There is however no duty to warn from obvious dangers of which the user knew or ought to have known. The manufacturer may also be obliged to amend the original warnings and/or instructions provided with the product if new facts come to light that would call for such an action.

4. Liability arising from a breach of organizational duty ('Verletzung der Organisationspflicht')

The manufacturer is generally obliged to implement organizational measures and procedures so as to avoid the establishment of sources of potential dangers to the best of his ability. This duty overlaps with other duties of care imposed onto the manufacturer, be they statutory or established by case law.

\section{Liability for development risk ('Verletzung der Produktbeobachtungspflicht')}

The manufacturer shall monitor for and react to new evidence pertaining to possible dangers arising from use of the product. Case law established that, under certain conditions, this duty also encompasses products by other parties (e.g. accessories) that, when used in combination with the product may give rise to dangers. Depending on the severity of the newly discovered danger the manufacturer may even be obliged to proceed with a product recall.

\subsubsection{Burden of Proof}

In German tort law - in particular pertaining to $\S \S 823$ I,II BGB - an alleviation of the burden of proof has been established by case law. For the courts acknowledged it would regularly amount to an undue burden (or even be infeasible) for the claimant to prove the alleged tortfeasor's fault (i.e. to establish that the conduct that led to the damages was intentional or negligent), as would be required following a strict interpretation of the law. It has therefore been established that providing so-called prima facie (Latin for 'at first sight') evidence for the alleged tortfeasor's fault and the causal relationship to the damages claimed suffices as long as no compelling contradictory explanation or evidence surfaces [42]. Pertaining to tortious product liability in particular, said alleviations eventually culminated into a full shift of the burden of proof ('Beweislastumkehr') in favor of the claimant. According to both case law upheld and established by the BGH and prevailing scholarly opinion said reversal in product liability matters is just, for the burden on the claimant would otherwise be disproportionate, especially in face of today's complex and intricate (distributed) manufacturing processes [41-44]. 
It may therefore be argued that tortious product liability, which as a matter of principle is based on faulty conduct, has effectively been tilted towards strict liability [41-43].

\subsubsection{Statute of Limitations and Caps on Damages}

The general limitation period of the BGB, i.e. three years under $§ 195$ BGB, applies and according to $§ 199$ I BGB begins with the end of the year in which the claim arose ( $\$ 199$ I No. 1 BGB) and the obligee obtains knowledge of the circumstances giving rise to the claim and of the identity of the obligor, or would have obtained such knowledge if he had not shown gross negligence (§ 199 I No. 2 BGB). It may be interrupted according to $\S 204$ BGB on the suspension of limitation periods as a result of the prosecution of rights. There are some exceptions however imposing longer but absolute (as in they begin on the date on which the act, breach of duty or other event that caused the damage occurred irrespective of the particular manner in which they arose and the knowledge thereof) limitation periods of either thirty years for injury to life, body, health or freedom (§ 199 II BGB) or ten years for most other claims ( 199 IV BGB). The reason for claims eventually becoming statute-barred is to provide legal certainty for all parties involved.

There are no caps on damages in the German law of torts. This constitutes a major differentiating factor with respect to other constructs, e.g. specific strict liability statutes such as ProdHaftG. Furthermore German law does not allow for punitive damages [45-48] and similarly rejects the concept of class action lawsuits [49].

\subsubsection{Protective Statute ( $\$ 823$ II BGB)}

Claims under $\S 823$ II for compensatory damages can be brought if they arose from a person's breach of a statute that is intended to protect another person. The claimant must prove that the violated statute awarded him protection from the specific act, breach of duty or other event that was perpetrated on him and gave rise to the damages being claimed ([41], p. 888). The importance of $\S 823$ II arises from the fact that it remarkably expands $\S 823$ I by including by reference various other statutes. By doing so it allows to recover damages such as purely economic losses that could not be recovered through $\S 823 \mathrm{I}$. It is therefore often referred to as the 'small general clause' of the German law of torts [41-43].

\subsection{Strict Product Liability}

Despite some alleviations pertaining to the burden of proof in tortious product liability matters have been established by case law (see Section 3.2.4), the fundamental distinction between fault-based liability under tort law and strict liability under special acts still holds.

\subsubsection{Origins and Common European Regulatory Framework}

Strict liability pertaining to defective products in Germany is regulated by the German Product Liability Act (GPLA) - Produkthaftungsgesetz (ProdHaftG) - which implements the EU Product Liability Directive 85/374/EC ('the Directive') and came into effect on 1 January 1990. With the Directive the European legislator essentially pursued the objectives of harmonizing (the at the time quite heterogeneous) national product liability statutes and strengthening consumer protection [42]

\subsubsection{The German Product Liability Act (ProdHaftG)}

$\S 1$ I ProdHaftG establishes the general principle of liability under the Act and provides that

In such case as a defective product causes a person's death, injury to his body or damage to his health, or damage to an item of property, the producer of the product has an obligation to compensate the injured person for the resulting damage. In case of damage to an item of property, this shall only apply if the damage was caused to an item of property other than the defective product and this other item of property is of a type ordinarily intended for private use or consumption und was used by the injured person mainly for his own private use or consumption. 


\subsubsection{Introductory Remarks}

The strict liability nature of the Act, in that - contrary to $\S \S 823 \mathrm{ff}$. BGB - culpable conduct is not a required element of the offense, is evidenced by § 1 I 1 ProdHaftG. Accordingly, under ProdHaftG the producer is liable for 'outliers' ('Ausreißer'), i.e. single products exhibiting a defect even though adequate and reasonable efforts were made to avoid the occurrence of such defects or hinder the injection of defective products into the stream of commerce. On the contrary, tortious product liability does not apply for outliers.

\subsubsection{Mandatory Nature and Applicability}

$\S 141$ ProdHaftG establishes the mandatory nature of the Act. If any attempts to circumvent, exclude or limit liability pursuant to the Act were to be made, they are null and void ( $\$ 142$ ProdHaftG). An enumeration of the rights and interests protected under the Act is provided by $\S 1$ I 1 ProdHaftG. Note that the enumeration is exhaustive, i.e. that only those rights and interests explicitly named are encompassed and thereby awarded protection. Similar to $\S 823 \mathrm{I}$ BGB, all the enumerated rights and interests are absolute rights and interests. $\S 1$ I 1 ProdHaftG however limits the scope of application more so than $\$ 823$ I BGB, which makes reference to 'other (absolute) rights', does. Furthermore, for the case of property damages, § 1 I 2 ProdHaftG provides that the producer shall only be liable for damages to items ordinarily intended for private use and under the facts of the specific case primarily used for said purposes by the injured person. Damage to the item itself is explicitly excluded as are any claims pertaining to pure economic loss. For the latter, basing the claim on $\S 823$ II BGB remains a viable option.

Further limitations or rather permitted exclusions of liability are codified in $\S \S 1$ II,III ProdHaftG. Due to their relevance pertaining to defense strategies and viable preemptive measures to counter claims brought pursuant to the Act they will be addressed separately in Section 3.3.10 below.

\subsubsection{Definition of 'Product' ( 2 ProdHaftG)}

$\S 2$ ProdHaftG provides a clear definition of what constitutes a product in terms of the Act and states that

a product within the meaning of this Act is all movables, even though incorporated into another movable or into an immovable, as well as electricity.

Accordingly, § 2 ProdHaftG requires a product to be a physical movable item ('bewegliche Sache'), which in turn begs the question of whether per se non-movable items such as 'intellectual goods', services, software etc. may be regarded as products in terms of $\S 2$ ProdHaftG or not. As for 'intellectual goods' (as such) and other services ('Dienstleistungen') the situation is clear: they are not products in terms of $\S 2$ due to the inherent lack of materialization. ProdHaftG therefore shall not apply. The picture is less clear when it comes to software, where in essence the same considerations outlined in Section 3.1.3 apply ${ }^{11}$.

\subsubsection{Definition of 'Product Defect' ( 3 ProdHaftG)}

$\S 3$ ProdHaftG provides the legislator's definition of product defects under the Act

(1) A product has a defect when it does not provide the safety which one is entitled to expect, taking all circumstances into account, in particular

a) its presentation,

b) the use to which it could reasonably be expected that it would be put,

c) the time when it was put into circulation.

11 The status of software materialized exclusively on volatile memory and even more so of software applications executed on third party servers is somewhat disputed as it is considered by some to more appropriately qualify as a service that is rendered rather than a product. There is however a trend towards affirming the applicability of ProdHaftG on software as a matter of principle [43]. To date according to the prevailing opinion a distinction is usually made between commercial off-the-shelf software ('Standardsoftware') and individually produced software ('Individualsoftware'), with the former being considered to be a product while the latter is classified as a service ('Dienstleistung') [50]. 
(2) A product is not defective for the sole reason that a better product is subsequently put into circulation.

We emphasize that the above definition of what constitutes a defect is remarkably different from the notion of material and/or legal defect discussed previously pertaining to contractual liability. In fact, as discussed in Section 3.1.2, the assessment of a product's defectiveness under contract law boils down to whether the subjective quality criteria stipulated to and agreed upon in the contractual agreement were met or not. Under contract law, objective quality criteria such as suitability for the customary use and the presence or absence of quality characteristics typically to be expected by a reasonable buyer for a product of this kind only become relevant in case the quality characteristics had not clearly been articulated in the respective contractual agreement. $\$ 3$ ProdHaftG on the other hand bases the determination of a product's defectiveness solely on objective criteria, most importantly on whether the reasonable safety expectations of the ordinary consumer were met or not. This is analogous to the 'consumer expectation test' known from U.S. product liability law. The reasonable safety expectations of the intended or expected user of the product, which the producer ought to account for, may be relaxed if the product is intended for use by and marketed to skilled professionals rather than to the general public, except when it is known or ought to be known or expected that the product may eventually find its way to the general public as well [43]. In other words, the producer ought to take a foreseeable misuse of the product into account.

\subsubsection{Definition of 'Producer' ( $\$ 4$ ProdHaftG)}

At first glance §823 I BGB and § 1 I 1 ProdHaftG may - ignoring for a moment the obvious difference pertaining to the applied standard of liability (i.e. fault-based vs. strict) - appear strikingly similar. A closer examination however readily confirms this not to be the case. For, while § 823 I BGB makes no restriction on the potential defendant(s) other that they shall be physical or legal persons, § 1 I 1 ProdHaftG explicitly provides that claims may only be brought against the producer. Therefore, the composition of the pool of potential defendants represents yet another divergence from tortious product liability, inevitably brought on by the dogmatic shift from fault-based to strict liability.

A claim based on tort law is brought against someone alleged to have infringed on absolute rights or interests of the claimant through an intentional or negligent act. Thus, notwithstanding that following the usual course of events in product liability cases such a wrongful act usually arises from a breach of the duty of care (the infamous 'Verkehrssicherungspflichten', as discussed in Section 3.2.2) by the manufacturer, as a matter of principle every person can be the addressee of a claim brought under $\S \S 823 \mathrm{ff}$. BGB.

The addressee of a claim brought under ProdHaftG on the other hand is necessarily the producer of the product. An enumeration of potential defendants, or rather a formal definition of the term producer, is provided by $\S 4$ ProdHaftG. Accordingly, a producer is any person who produced the final product, a part thereof or a needed raw material (§ 4 I 1 ProdHaftG).

A producer is also anyone who by putting his name, trademark or other distinguishing feature on the product presents himself as its producer (\$ 4 I 2 ProdHaftG)

i.e. the so-called 'quasi-producer' ('Quasi-Hersteller'). Furthermore, for products or components or raw materials that become part of the final product manufactured outside the European Economic Area, anyone who imports said product, component or raw material in the course of his regular business activity is considered to be the producer ( $\$ 4$ II ProdHaftG). To ensure consumer protection, liability may be passed further down the commercial chain to wholesale distributors and eventually to the retailer, i.e. where the producer of the product cannot be identified they may be considered as being the producer unless they provide, within a month upon receiving claimant's request, the identity of the actual producer or in the alternative of the supplier they obtained the product from ( $\$ 4$ III 1 ProdHaftG). If accordingly multiple parties liable for the same damage have been identified, they shall be liable jointly and severally ( $\$ 51$ ProdHaftG). Their respective liability and the extent of compensation to be paid as well as possibilities for redress are provided in $\S 52 \mathrm{ProdHaftG}$, which also provides 
that the provisions of $\S 421-426$ BGB shall apply.

In conclusion, while the strict liability nature of the Act limits the pool of potential defendants to the producer, the definition of the term 'producer' has purposely been widened to ensure that the claimant may easily discern an addressee for his claim.

\subsubsection{Burden of Proof, Statute of Limitations and Expiry of Claims}

Pursuant to $§ 1$ IV 1 ProdHaftG the claimant bears the burden of proof pertaining to the defectiveness of the product, the damages caused by said defect and the causal relationship between the two. Any further burden of proof is on the defendant ( $\$ 1$ IV 2 ProdHaftG).

Pursuant to $\S 12$ I ProdHaftG claims brought under $\S 1$ of the Act become statute-barred three years from the day the claimant became aware or ought to have become aware of the damage, the defect and the identity of the party liable for the damage. This resembles the provisions of § 199 I BGB with the exception that pursuant to $\S 199$ I BGB the standard limitation period commences at the end of the year in which the claim arose and the obligee obtained or ought to have obtained knowledge of the identity of the obligor as opposed to the immediate commencement under ProdHaftG [42]. The limitation period is to be suspended if negotiations between the parties on the compensation of the damage are pending ( 12 II ProdHaftG) whereas in all other respects, the provisions of the German Civil Code on limitation shall apply mutatis mutandis (§ 12 III ProdHaftG).

Furthermore, pursuant to $\S 13$ I 1 ProdHaftG claims expire ten years from the date the producer put the product into circulation, except for when legal proceedings on the claim are pending ( $\$ 13$ I 2 ProdHaftG). According to the EuGH, a product is considered to have been put into circulation if it has left the manufacturing process in its final and ready for use state and entered into a process of commercialization, irrespective of whether it is sold and distributed directly to the consumer or not (see, e.g. [42], p. 314).

\subsubsection{Limits on the Extent of Liability}

As with other strict liability acts, ProdHaftG provides liability limitations and caps on damages. First and foremost, the producer's obligation to compensate damages to property only attaches if private property was damaged ( 1 I 2 ProdHaftG) and damages to said property up to an amount of 500 Euros shall be paid for by the injured party ( $§ 11$ ProdHaftG). Purely financial loss as well as damages to the defective product itself are not compensable.

§ 6 I ProdHaftG provides that § 254 BGB ('contributory negligence') shall apply whenever fault on the part of the injured party contributed to the occurrence of the damage. The referenced BGB provision provides that the extent of compensation to be paid shall depend on the particular circumstances of the case, in particular to what extent the damage was caused mainly by one or the other party.

$\S 10$ I ProdHaftG provides a cap on damages for personal injuries caused by a product or by identical products with the same defect of 85 million Euros. If several parties were injured and the combined amount of damages were to exceed said 85 million Euros, the individual compensation shall be reduced pro-rata to the maximum total given ( $\$ 10$ II ProdHaftG).

Note that $\S 82$ ProdHaftG allows for the recovery of damages for pain and suffering. § 253 II BGB applies accordingly.

Finally, § 15 II ProdHaftG provides, liability on the basis of other provisions remains unaffected, except for medicinal products ( $\$ 15$ I ProdHaftG).

\subsubsection{Available Defenses}

Typically the defendant may invoke one of the exclusions of liability provided by §§ 1 II-III ProdHaftG, which read as follows:

\section{(2) The producer's liability obligation is excluded if}


1. he did not put the product into circulation,

2. under the circumstances it is probable that the defect which caused the damage did not exist at the time when the producer put the product into circulation,

3. the product was neither manufactured by him for sale or any other form of distribution for economic purpose nor manufactured or distributed by him in the course of his business,

4. the defect is due to compliance of the product with mandatory regulations at the time when the producer put the product into circulation or

5. the state of scientific and technical knowledge at the time when the producer put the product into circulation was not such as to enable the defect to be discovered.

(3) The obligation to pay damages of the producer of a component part is also excluded if the defect is attributable to the design of the product in which the component has been fitted or to the instructions given by the manufacturer of the product. The first sentence shall apply to the producer of a raw material mutatis mutandis.

The 'state of the art defense' pursuant to $\S 1$ II No. 5 ProdHaftG is arguably of the greatest practical relevance. It shall be emphasized, however, that this defense can only be asserted pertaining to design defects, not manufacturing defects [51].

The strict liability nature of the Act demands the objective assessment of whether the state of the scientific and technical knowledge at the time the product was put into circulation would have allowed the defect to be discovered (and thus avoided) or not. It is therefore irrelevant what the 'industry standard' (i.e. what the rest of the industry had done to ensure product safety) was. It is equally irrelevant whether the manufacturer knew or ought to have known of the developments in his field that would have allowed him to discover the defect. In other words, the objective feasibility to discover the defect subject to the actual scientific and technical knowledge at the time decides on whether liability attaches or not while the subjective ability of the defendant to do so has no bearing.

It is also important to note that even if the producer can avoid liability pursuant to ProdHaftG by successfully invoking the state of the art defense, he may still be held liable for breach of his post-marketing duty to monitor for development risk and possibly recall the product under tort law (see Section 3.2.3).

\subsection{Comparison of ProdHaftG and Tortious Product Liability}

Prior to the introduction of ProdHaftG in 1990, all product liability cases in Germany were based on tort law, i.e. the well-established delict provision of the BGB, in particular $\$ 823$ I BGB. Note that the two are not mutually exclusive, but coexist and can operate simultaneously. Thus, the pros and cons of either one should carefully be evaluated pertaining to the specific facts of the case at hand.

Table 3 provides a comparison of both forms of liability and highlights their most important characteristics and peculiarities. Most notably, ProdHaftG imposes caps on damages and a deterrent fee for the recovery of property damage, furthermore it does not allow for the recovery of damages to items for industrial or commercial purposes or the recovery of purely financial loss. Accordingly, tortious product liability (especially through $\S 823$ II BGB) is applicable in a much broader scope and without caps on damages or deterrent fees, yet it requires culpable conduct (harder to establish) and thus e.g. does not apply for damages that arose from so-called outliers. 
Table 3. Comparison of ProdHaftG and Tortious Product Liability

\begin{tabular}{|c|c|c|}
\hline & Tortious Product Liability & Strict Product Liability \\
\hline Statutory basis & $\S \S 823$ ff. BGB & $\S \S 1$ ff. ProdHaftG \\
\hline Liability rule & Fault-based & Strict \\
\hline Contractual relationship & \multicolumn{2}{|c|}{ Not required } \\
\hline Protected rights and interests & $\begin{array}{l}\text { Life, body, health, freedom, } \\
\text { property and other absolute rights } \\
\text { ( } \$ 823 \text { I BGB) } \\
\text { Statutes that protect another } \\
\text { individual ( } \$ 823 \text { II BGB) }\end{array}$ & $\begin{array}{l}\text { Life, body, health, and private } \\
\text { property ( } \$ 1 \text { I ProdHaftG) }\end{array}$ \\
\hline Liability for outliers & - & + \\
\hline Claimant & \multicolumn{2}{|c|}{$\begin{array}{l}\text { Directly afflicted person } \\
\text { Indirectly afflicted person (loss of support, funeral expenses) }\end{array}$} \\
\hline Defendant & $\begin{array}{l}\text { Anyone who culpably breaches a } \\
\text { duty of care or a protective statute }\end{array}$ & $\begin{array}{l}\text { Producer ( } \$ 4 \text { ProdHaftG) } \\
\text { (i.e. manufacturer of final } \\
\text { product or of components or } \\
\text { raw materials incorporated into } \\
\text { the final product, quasi-producer, } \\
\text { importer, distributor, retailer) }\end{array}$ \\
\hline Liability trigger & $\begin{array}{l}\text { Culpable breach of a duty of care } \\
\text { or protective statute }\end{array}$ & Product defect \\
\hline Claimant's burden of proof & $\begin{array}{l}\text { Breach of duty of care or } \\
\text { protective statute, damages and } \\
\text { causal relationship between the } \\
\text { two }\end{array}$ & $\begin{array}{l}\text { Product defect, damages and } \\
\text { causal relationship between the } \\
\text { two }\end{array}$ \\
\hline Defendant's burden of proof & \multicolumn{2}{|c|}{ Any further burden of proof } \\
\hline Caps on damages & - & 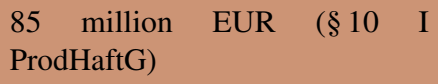 \\
\hline Deterrent fee & - & $\begin{array}{l}\text { for property damage: } 500 \text { EUR } \\
(\S 11 \text { ProdHaftG) }\end{array}$ \\
\hline Limitation period & \multicolumn{2}{|c|}{3 years } \\
\hline $\begin{array}{l}\text { Commencement of limitation } \\
\text { period }\end{array}$ & $\begin{array}{l}\text { from the day the claimant became } \\
\text { aware or ought to have become } \\
\text { aware of the damage, the defect } \\
\text { and the identity of the party liable } \\
\text { for the damage }\end{array}$ & $\begin{array}{l}\text { from the end of the year in which } \\
\text { the claim arose and the obligee } \\
\text { obtained or ought to have obtained } \\
\text { knowledge of the identity of the } \\
\text { obligor }\end{array}$ \\
\hline Extinction of claims & $\begin{array}{l}30 \text { years for injury to life, body, } \\
\text { health or freedom ( } \$ 199 \text { II BGB) } \\
10 \text { years for other claims ( } \$ 199 \text { IV } \\
\text { BGB) }\end{array}$ & $\begin{array}{l}10 \text { years from the date the } \\
\text { producer put the product into } \\
\text { circulation }(\$ 13 \text { I } 1 \text { ProdHaftG) }\end{array}$ \\
\hline
\end{tabular}

\section{Lessons Learned and Some Suggestions}

The strive for ever improved and optimal designs is undoubtedly one - if not the major - force driving the fast pace of innovation throughout all engineering disciplines we have consistently witnessed over the last 
decades. It is, however, important to realize and remain aware of that inextricably bound to it is the danger of (perhaps unwillingly and unwittingly) invoking statistical assumptions and tools that may at first glance appear appropriate, yet not withstand a higher level of scrutiny. Accordingly, while it would certainly be inappropriate and counterproductive to demonize striving for optimality and to instead advocate an extremely conservative approach in the spirit of better safe than sorry, the case can be made that seemingly less attractive alternatives such as nonparametric statistics or at least carefully selected robust approaches should not be dismissed but rather evaluated in full appreciation of the far-reaching ramifications design defects may and often do have, as we exhaustively described in this paper.

We are by no means the first to raise questions as to the appropriateness of a stoic pursuit of optimality. In fact, this very issue has been raised before in the literature, among others notably by some prominent statisticians, in fact two of the very fathers of contemporary robust statistics, namely John W. Tukey and Peter J. Huber. Both papers $[52,53]$ were largely ignored by statisticians and practitioners alike, which is certainly unfortunate, for the important message they convey would have deserved much more widespread attention and recognition.

Therefore, while we take no such extreme stance on the matter as Tukey and Huber (in said papers), we deem it appropriate to begin this final Section recalling some of the most important points raised by these very influential scholars.

\subsection{The Curse of Optimality}

In his 1962 paper on 'The Future of Data Analysis' [52] Tukey discussed in detail the 'dangers of optimization' and summarized the problem solving approach encountered in the discipline as one starting out with a rough comparison of efficacy of a set of competing techniques, followed by further comparison in terms of a precise - and according to Tukey thereby inherently inadequate - criterion finally yielding to solving an optimization problem based on a precise and similarly inadequate criterion. Tukey argues that at the root of the problem is the fact that optimization comes natural to mathematicians and has them often disregard that the optimum by definition depends upon the assumption of criteria whose selection inherently involves a degree of (subjective) judgment (see ([52], p. 9)).

To put it in the words of George E. Kimball

There is a further difficulty with the finding of 'best' solutions. All too frequently when a 'best' solution to a problem has been found, someone comes along and finds a still better solution simply by pointing out the existence of a hitherto unsuspected variable. [54]

Equally controversial and provocative statements can be found in Peter J. Huber's 2009 paper 'On the Non-Optimality of Optimal Procedures' [53] where he expresses that the papers of Fisher and Neyman-Pearson imprinted an entire generation of statisticians with an often too uncritical love of optimality (see [53], p. 32). Huber cautions the reader that while optimality results are important, for they provide performance boundaries and thus allow to ascertain whether there is still room for improvements, they are too dangerous to be used as a general rule. Similar to Tukey, Huber also cautions against optimizing a single aspect to the detriment of all the others and emphasizes that there are no clear-cut rules as how to actually apply optimal procedures since uncircumventable trade-offs requiring human judgment are involved (see [53], p. 44).

\subsection{Some General Recommendations}

Implicitly, the case for the use of suboptimal nonparametric and robust statistics to control and influence product liability exposure by making allowances for various legal constraints, has already been made in the preceding Sections through a carefully drafted formulation of the major problems inherent to statistical modeling and by thoroughly analyzing and elaborating on the current German (and European) product liability framework. Unfortunately, there is no one size fits all rule to be provided. In fact, it is in the very nature of laws and statutes that, even when carefully and properly drafted, they remain open to interpretation and their implications need to be assessed on a case-by-case basis (see, e.g. [55]). Therefore, this Section will purposely be limited to providing some general guidance in the form of unified picture obtained by synergistically fusing the important statistical 
as well as legal aspects identified and elaborated on in the preceding Sections.

What follows is essentially a concise list (without claiming to be exhaustive) of key aspects likely to be relevant in most product design and development tasks (involving statistics).

1. Avoid contractual liability, i.e. start by assuring that contractual obligations are met (i.e. specifications stipulated in the contractual agreement (if there is one))

- Recall that a product's defectiveness under contract law boils down to whether the agreed upon subjective quality criteria are met or not (see Section 3.1.2) and objective criteria only come into play if such criteria were not clearly articulated in the contractual agreement.

- Roughly speaking, avoiding a breach of contractual obligations is easier to assure, for there is ample room for individually negotiated contract terms.

- With 'reasonable product safety' being i) a typical contractual duty; and ii) an aspect that will be considered in later steps (tortious/strict product liability), the focus here shall be on assuring the agreed upon (subjective) quality is delivered.

- Keep in mind though that this may yield to favoring a solution that turn out to be problematic in later steps, so be conservative and forward-looking.

- Recall the tight boundaries on the possibility to exclude liability (see Section 3.1.5)

2. Tortious Product Liability: pay close attention to the various duties of care under $\S 823$ I BGB established by case law (see Section 3.2.3).

- The greatest danger lies in liability due to acts of omission.

- Liability due to design defect should be of utmost concern. In fact, design defects are the most common (and obvious) point of attack in product liability litigation.

- Your design ought to consider not only the expected conditions and the intended use but also potentially unlikely (but strongly deviating) conditions and potential improper use.

- Do not, e.g., merely rely upon the fact that your solution is based on a high-breakdown robust procedure, for these are often unstable or otherwise inappropriate and the breakdown point is an important, yet somewhat controversial, metric (see Section 2.3.4).

- Consider not striving for an 'optimal' solution as such optimality inevitably comes at the detriment of other aspects, which is likely to constitute a design defect in and of itself.

- Also pay attention to the other duties of care, particularly defective instructions, breach of organizational duty and development risk.

- Establish and maintain a good culture and practice of quality control and document it scrupulously.

3. Strict Product Liability: be aware of your strict (as in not fault-based) liability and make yourself familiar with the available legally recognized justifications (see Section 3.3.10).

- Of particular relevance is $\S 1$ II No. 5 ProdHaftG, the 'state of the art defense'.

It would be beyond the scope of this paper to examine specific, clearly defined problems for which then problem-specific recommendations could be derived. Nevertheless a strong case for the use of suboptimal 
robust or even nonparametric approaches can certainly be made from a perspective of reducing product liability exposure, due to the fact that statistical modeling assumptions are virtually always violated in real world scenarios and that optimality inevitably comes at the detriment of other perhaps aspects.

It is equally important, however, to emphasize that, as discussed in detail in Section 3, advocating for the general adoption of the here outlined practices would be unjustified. For, as it pertains to tortious and strict product liability, it is only certain types of problems where this is advisable since for said liability to attach, absolute rights or interests have to be infringed.

In numerous consumer electronics application scenarios for instance the performance (from the perspective of the end-user) may be compromised as a result of sloppy design work, which would potentially amount to a breach of contractual duties for which the buyer could demand cure from the seller. However, usually in such a scenario absolute rights or interests would not be jeopardized thus not granting the buyer any product liability cause of action.

On the other hand, consider the case of increasingly popular fitness and well-being apps and devices, e.g. for optical heart rate (HR) monitoring by means of Photoplethysmography (PPG) [56]. While such apps and devices currently are not subject to the medical devices regulatory framework (see, e.g. [57,58], product liability issues are a major concern [59-61] and a plethora of signal processing challenges which, if not tackled appropriately, are likely to infringe on absolute rights and interests exist [59].

\section{Discussion}

Legal concerns regarding IoT in general have to date almost exclusively been raised regarding IT-security and data privacy issues just as concerns regarding the reliance on simplistic and inappropriate statistical models and the often counterproductive obsession with optimality have been raised in mathematical statistics.

To the best of our knowledge, this paper is the first to draw attention to and explore some often overlooked or oversimplified dangers and pitfalls that enter the equation when product design heavily relies on statistical modeling. In particular, through a diligent analysis of both statistical and legal aspects we will explore how statistically optimal procedures may yield far from optimal outcomes in terms of product liability when applied to actual real life problems and why suboptimal nonparametric or robust approaches may constitute better alternatives.

It appears in order to emphasize some limitations of this work, most notably that rather than clear solutions only very general recommendations were proposed. This is however inevitable due to the very nature of laws and statutes that will to some extent always remain open to interpretation thus requiring their implications to be assessed on a case-by-case basis.

Acknowledgments: The work of M. Lang was supported by the 'Excellence Initiative' of the German Federal and State Governments and the Graduate School of Excellence Computational Engineering at Technische Universtät Darmstadt. The views expressed in this article are solely those of the author in his private capacity and do not necessarily reflect the views of Technische Universtät Darmstadt or any other organization.

Conflicts of Interest: The author declares no conflict of interest.

\section{Abbreviations}

The following abbreviations are used in this manuscript: 


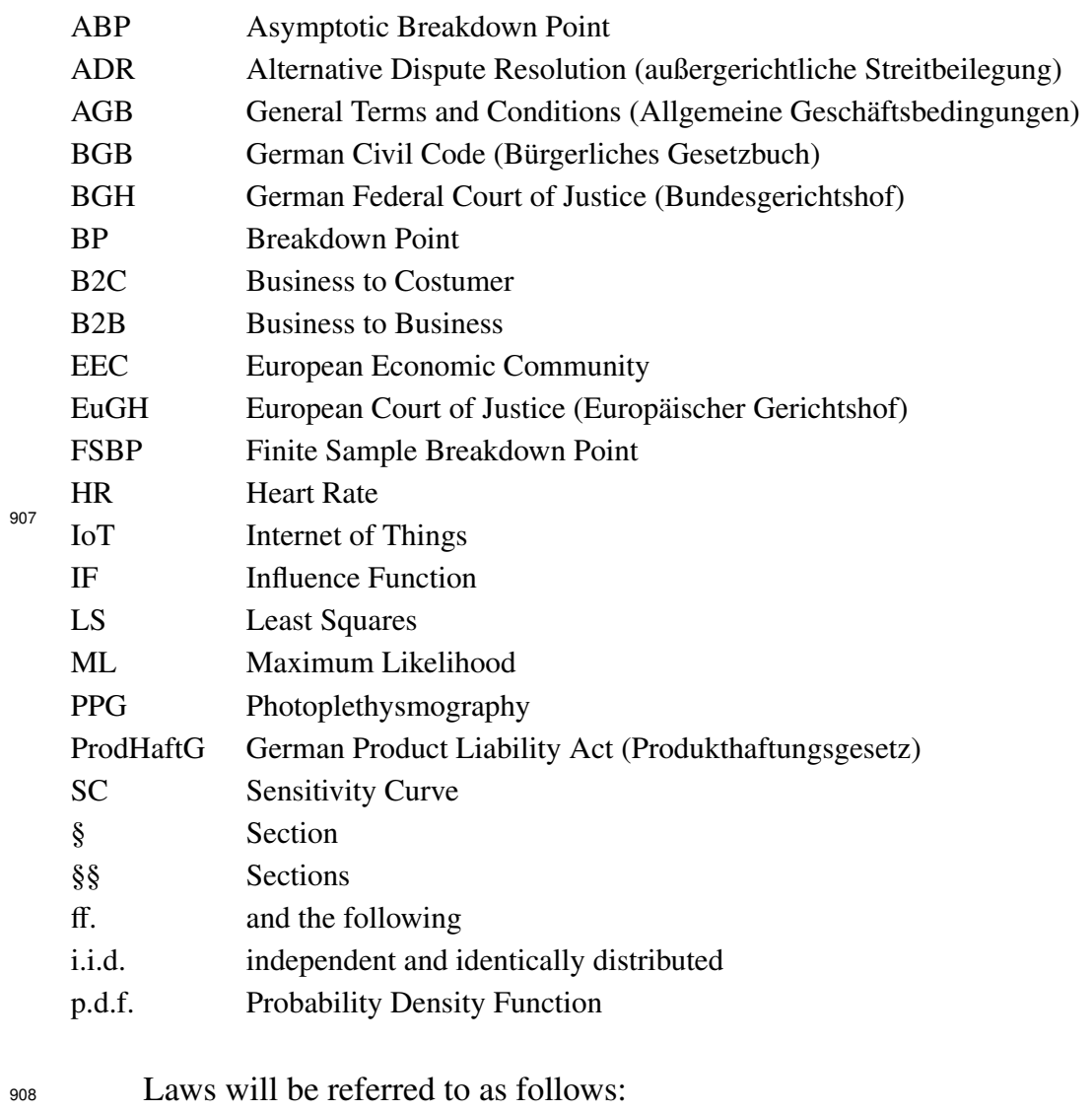

§ 812 I 1 Alt. 2 BGB

reads as

Section 812, subsection 1, sentence 1, 2nd alternative of the German Civil Code

$$
\S 434 \text { I } 2 \text { No. } 2 \text { BGB }
$$

reads as

Section 434, subsection 1, sentence 2, number 2 of the German Civil Code

$$
\S \S 123-456 \mathrm{BGB}
$$

reads as

Sections 123 to 456 of the German Civil Code

\section{$\S \S 1$ ff. ProdHaftG}

reads as

Section(s) 1 and the following of the German Product Liability Act.

1. Fisher, R.A. On the Mathematical Foundations of Theoretical Statistics. Philosophical Transactions of the Royal Society of London A: Mathematical, Physical and Engineering Sciences 1922, 222, 309-368.

2. Gauss, C.F. Theory of the motion of the heavenly bodies moving about the sun in conic sections: a translation of Gauss's 'Theoria motus.' With an appendix by C. H. Davis; Boston, Little, Brown and company, 1857.

3. Gorroochurn, P. Classic Problems of Probability, 1st ed.; John Wiley \& Sons Inc., 2012.

4. Rathie, P.N. Normal Distribution, Univariate. In International Encyclopedia of Statistical Science; Lovric, M., Ed.; Springer Berlin Heidelberg, 2011; pp. 995-999.

5. Stigler, S.M. Mathematical Statistics in the Early States. The Annals of Statistics 1978, 6, 239-265. 
6. Hald, A., Ed. A History of Parametric Statistical Inference from Bernoulli to Fisher, 1713-1935, 1st ed.; Springer, 2007.

7. Karlgaard, C.D. Robust Adaptive Estimation for Autonomous Rendezvous in Elliptical Orbit. PhD thesis, Virginia Polytechnic Institute and State University, 2010.

8. Kohar, R. Basic Discrete Mathematics: Logic, Set Theory, and Probability; World Scientific Publishing Company, 2016.

9. Hampel, F.R.; Ronchetti, E.M.; Rousseeuw, P.J.; Stahel, W.A. Robust Statistics: The Approach Based on Influence Functions; Wiley, 1985.

10. Huber, P.J. The 1972 Wald Lecture Robust Statistics: A Review. The Annals of Mathematical Statistics 1972, 43, 1041-1067.

11. Box, G.E.P. Non-Normality and Tests on Variances. Biometrika 1953, 40, 318-335.

12. Ronchetti, E. Robust Inference. In International Encyclopedia of Statistical Science; Lovric, M., Ed.; Springer Berlin Heidelberg, 2011; pp. 1240-1242.

13. Huber, P.J. Robust Statistics. In International Encyclopedia of Statistical Science; Lovric, M., Ed.; Springer Berlin Heidelberg, 2011; pp. 1248-1251.

14. Tukey, J.W. A survey of sampling from contaminated distributions. Contributions to probability and statistics $\mathbf{1 9 6 0}$, $2,448-485$.

15. Morgenthaler, S. A survey of robust statistics. Statistical Methods and Applications 2007, 15, 271-293.

16. Hampel, F.R. Robust Inference. Research Report 2000, 93. ETH Zürich.

17. Huber, P.J. Robust statistics; Wiley, 1981.

18. Huber, P.J.; Ronchetti, E.M. Robust statistics, 2nd ed.; Wiley, 2009.

19. Huber, P.J. Robust Estimation of a Location Parameter. Ann. Math. Statist. 1964, 35, 73-101.

20. Heritier, S.; Cantoni, E.; Copt, S.; Victoria-Feser, M. Robust Methods in Biostatistics, 1st ed.; Wiley, 2009.

21. Maronna, R. Robust Statistical Methods. In International Encyclopedia of Statistical Science; Lovric, M., Ed.; Springer Berlin Heidelberg, 2011; pp. 1244-1248.

22. Tukey, J.W. Exploratory Data Analysis, 1st ed.; Pearson, 1970.

23. Hampel, F.R. Contributions to the theory of robust estimation. PhD thesis, University of California, Berkeley, 1968.

24. Hampel, F.R. The Influence Curve and Its Role in Robust Estimation. Journal of the American Statistical Association 1974, 64, 383-393.

25. Davies, P.L.; Gather, U. The Breakdown Point - Examples and Counterexamples. REVSTAT Statistical Journal 2007, 5, 1-17.

26. Donoho, D.L.; Huber, P.J. The notion of breakdown point. A Festschrift for Erich L. Lehmann 1983, pp. 157-184.

27. Härdle, W. Applied Nonparametric Regression, 1st ed.; Cambridge University Press, 1990.

28. Conover, W.J. Practical Nonparametric Statistics, 3rd ed.; Wiley, 1999.

29. Arbuthnot, J. An argument for divine providence, taken from the constant regularity observ'd in the births of both sexes. Philos Trans R Soc 1710, 27, 186-190.

30. Sprent, P. Sign Test. In International Encyclopedia of Statistical Science; Lovric, M., Ed.; Springer Berlin Heidelberg, 2011; pp. 1316-1318.

31. McKean, J.W.; Hettmansperger, T.P. Rank-Based Analysis of Linear Models and Beyond: A Review. In Robust Rank-Based and Nonparametric Methods; Liu, R.G.; McKean, J.W., Eds.; Springer International Publishing, 2016; pp. 1-24.

32. Wilcoxon, F. Individual Comparisons by Ranking Methods. Biometrics Bulletin 1945, 1, 80-83.

33. Mann, H.; Whitney, D. On a Test of Whether one of Two Random Variables is Stochastically Larger than the Other. The Annals of Mathematical Statistics 1947, 18, 50-60.

34. Hodges, J.L.; Lehmann, E.L. The Efficiency of Some Nonparametric Competitors of the t-Test. The Annals of Mathematical Statistics 1956, 27, 324-335.

35. Hollander, M.; Wolfe, D.A. Nonparametric Statistical Methods, 2nd ed.; Wiley, 1999.

36. Govindarajulu, Z. Nonparametric Inference, 1st ed.; World Scientific Publishing Company, 2007.

37. Jurečková, J.; Sen, P.K.; Picek, J. Methodology in Robust and Nonparametric Statistics, 1st ed.; CRC Press, 2012.

38. Hodges, J.L.; Lehmann, E.L. Estimates of Location Based on Rank Tests. The Annals of Mathematical Statistics 1963, 34, 598-611. 
39. Klindt, T.; Wende, S.; Burrer, S.; Schaloske, H.; Żdanowiecki, K. (Produkt-) Haftung/Haftung für Softwaremängel und versicherungsrechtliche Aspekte. In Digitalisierte Wirtschaft/Industrie 4.0, 1st ed.; Bräutigam, P.; Klindt, T., Eds.; Noerr LLP, 2015; chapter 7.

40. Greiner, S. Schuldrecht Besonderer Teil: Vertragliche Schuldverhältnisse, 1st ed.; Springer, 2011.

41. Markesinis, B.; Unberath, H. The German Law of Torts: A Comparative Treatise, 4th ed.; Hart Publishing, 2002.

42. Fuchs, M.; Pauker, W. Delikts- und Schadensersatzrecht, 8th ed.; Springer, 2012.

43. Staake, M. Gesetzliche Schuldverhältnisse, 1st ed.; Springer, 2014.

44. Köhler, H. Bürgerliches Gesetzbuch BGB, 79th ed.; dtv Verlagsgesellschaft, 2017.

45. Behr, V. Punitive Damages in America and German Law-Tendencies towards Approximation of Apparently Irreconcilable Concepts. Chi.-Kent L. Rev. 2003, 78, 105.

46. Koziol, H. Punitive Damages-A European Perspective. La. L. Rev. 2007, 68, 741.

47. Tolani, M. U.S. Punitive Damages Before German Courts: A Comparative Analysis with Respect to the Ordre Public. Annual Survey of International \& Comparative Law 2011, 17.

48. Fiebig, A.R. The Recognition and Enforcement of Punitive Damage Awards in Germany: Recent Developments. Ga. J. Int'l \& Comp. L. 1992, 22, 635.

49. Foerster, V.; Pahl, T.; Foerster, T. Handbook of Product Liability / Recall / Insurance in Germany, 1st ed.; Tredition GmbH, 2012.

50. Bergkamp, L.; Faure, M.; Hinteregger, M.; Philipsen, N., Civil Liability in Europe for Terrorism-Related Risk. In Civil Liability in Europe for Terrorism-Related Risk; Cambridge Studies in International and Comparative Law, Cambridge University Press, 2015.

51. Moelle, H.; Behrendt, P. Germany. In International Comparative Legal Guide to: Product Liability 2016, 14th ed.; Dodds-Smith, I., Ed.; Global Legal Group Ltd, 2016; chapter 13.

52. Tukey, J.W. The Future of Data Analysis. The Annals of Mathematical Statistics 1962, 33, 1-67.

53. Huber, P.J., On the Non-Optimality of Optimal Procedures. In Optimality; Rojo, J., Ed.; Institute of Mathematical Statistics, 2009; Vol. 57, Lecture Notes-Monograph Series, pp. 31-46.

54. Kimball, G.E. A Critique of Operations Research. Journal of the Washington Academy of Sciences 1958, 48, 33-37.

55. Millard, C.; Hon, W.K.; Singh, J. Internet of Things Ecosystems: Unpacking Legal Relationships and Liabilities. 2017 IEEE International Conference on Cloud Engineering (IC2E), 2017, pp. 286-291.

56. Allen, J. Photoplethysmography and its application in clinical physiological measurement. Physiological Measurement 2007, 28, R1-R39.

57. Quinn, P. The EU commission's risky choice for a non-risk based strategy on assessment of medical devices. Computer Law \& Security Review 2017, 33, 361-370.

58. Lang, M. Heart Rate Monitoring Apps: Information for Engineers and Researchers About the New European Medical Devices Regulation 2017/745. JMIR Biomed Eng 2017, 2, e2.

59. Lang, M. Beyond Fitbit: A Critical Appraisal of Optical Heart Rate Monitoring Wearables and Apps, their Current Limitations and Legal Implications. Alb. L. J. Sci. \& Tech. 2018, 28. forthcoming.

60. Terry, N.P.; Wiley, L.F. Liability for Mobile Health and Wearable Technologies. Annals Health L. 2016, 25.

61. Thierer, A.D. The Internet of Things and Wearable Technology: Addressing Privacy and Security Concerns without Derailing Innovation. Rich. J. L. \& Tech. 2015, 21. 